\title{
Use of photosensitive polyimide for deep x-ray lithography
}

\author{
V. White, R. Ghodssi, C. Herdey, D. D. Denton, ${ }^{\text {a) }}$ and L. McCaughan \\ Department of Electrical and Computer Engineering, University of Wisconsin, Madison, Wisconsin 53706
}

(Received 22 September 1994; accepted for publication 3 February 1995)

\begin{abstract}
In this letter, a method is outlined and results presented for an x-ray lithography micromachining process that offers a greatly improved sensitivity over the LIGA process. This process is based on photosensitive polyimide (PPI), which is a commercial photoresist typically used as a passivation layer or dielectric material in the semiconductor industry. The main benefit of this process is its high sensitivity, which is approximately two orders of magnitude greater than that of the PMMA used in the LIGA process. Using a synchrotron radiation $\mathrm{x}$-ray source, we have achieved resist patterns over $1000 \mu \mathrm{m}$ thick. The capability has also been demonstrated for aspect ratios over 10, as well as the ability to print linewidths down to $0.5 \mu \mathrm{m}$. (C) 1995 American Institute of Physics.
\end{abstract}

We are investigating alternatives to the PMMA-based LIGA process for $\mathrm{X}$-ray lithography-based micromachining. ${ }^{1,2}$ PMMA is the benchmark for resists in micromachining. A promising alternative to PMMA is the photosensitive polyimide family, henceforth referred to as photosensitivity polyimide (PPI). A major motivation for the search for new materials is that PMMA requires very large doses for each exposure. ${ }^{3}$ A useful measure of resist sensitivity is the absorbed x-ray energy per unit volume in the resist (in contrast to energy per unit area, or surface dose). Our empirical data indicate that to fully expose PMMA satisfactorily requires an $\mathrm{x}$-ray exposure with an absorbed energy dose of $\sim 5500 \mathrm{~J} / \mathrm{cm}^{3}$, although others have reported a lower value. ${ }^{1}$ The new PPI process presented here requires an absorbed energy dose on the order of $50 \mathrm{~J} / \mathrm{cm}^{3}$.

Allen et al. developed a process for a micromachining technique that uses photosensitive polyimide exposed by a standard ultraviolet optical printer. ${ }^{4}$ Devices $50 \mu \mathrm{m}$ in height with aspect ratios greater than eight have been reported. ${ }^{4}$ Our process extends Allen's UV work to the deep x-ray region and to much greater resist thicknesses. It yields approximately a two order of magnitude increase in sensitivity compared to the traditional PMMA-based LIGA micromachining process.

Dupont Pyralin ${ }^{\odot} 2411$ photosensitive polyimide, which is a negative resist, was used in this work. ${ }^{5}$ For very thick layers, multiple spins have been used with up to $100 \mu \mathrm{m}$ per application. The initial layer of Pyralin 2411 was spun on a clean silicon substrate. For multiple layers, a one-half hour dry bake at $90{ }^{\circ} \mathrm{C}$ in a convection oven was used between resist applications. After the final coat, the sample was baked for two more hours at $90{ }^{\circ} \mathrm{C}$. For thinner resist applications, the polyimide can be thinned with $n$-methyl-pyrollidinone (NMP). Spray development was used with a developer made from a 1:1 mixture of $n$-gamma buterol:NMP, followed by a rinse of acetone and a nitrogen blowdry. Figure 1 shows a result of an x-ray generated resist profile $80 \mu \mathrm{m}$ high with an aspect ratio of over 10 . Note that the sidewall structure is very vertical but, at the base of the resist structure there is a significant "foot" structure. This "foot" appeared in every thick resist sample exposed to $\mathrm{x}$ rays. This exposure took

${ }^{a)}$ Electronic mail: denton@engr.wisc.edu $\sim 15 \mathrm{~min}$ and the sample was exposed with the $800 \mathrm{MeV}$ beam at Aladdin (with a peak intensity at $\sim 12 \AA$ ). For comparison, a similar depth exposure in PMMA with the same energy beam would require over $10 \mathrm{~h}$ to complete.

To characterize PPI, dose versus developed resist thickness measurements were taken on 4 in. wafers. The wafers were exposed in a $5 \times 5$ grid array with graduated exposure dose. The resist was then developed until clear (nominal development time), and measured with an Alpha-Step profilometer. Following this, it was developed and profiled again to gain further understanding of the development processes. The data were taken on resist samples of 0.65 and $17.5 \mu \mathrm{m}$ thick. Figures 2 and 3 show resist thickness versus surface dose for the 0.65 and $17.5 \mu \mathrm{m}$ thick samples, respectively. The noise in the data is attributed to nonuniformities in spin coating thickness over the $4 \mathrm{in}$. wafer. A full analysis of the data is well beyond the scope of this letter. However, a number of characteristics can be surmised. In both cases, the exposure threshold is $\sim 400 \mathrm{~mJ} / \mathrm{cm}^{2}$. We also observe a reduction in resist thickness after development. For the 0.65 $\mu \mathrm{m}$ initial thickness sample (Fig. 2), there is a resist loss of

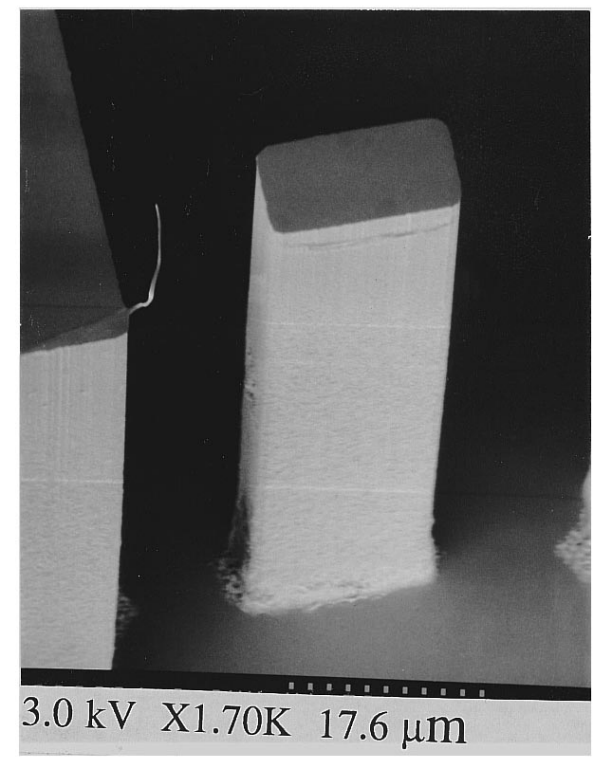

FIG. 1. Resist structures $80 \mu \mathrm{m}$ high given about $2 \%$ of the dose a corresponding PMMA exposure would require. It has an aspect ratio of over 10. 


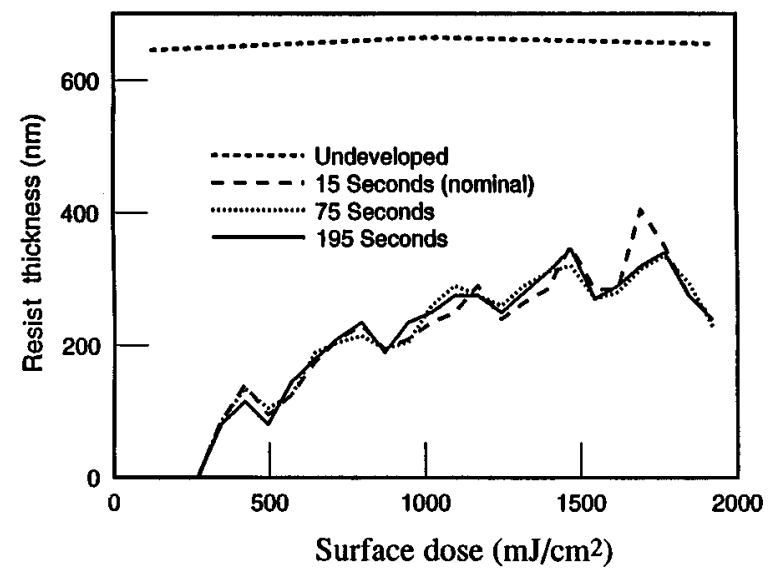

FIG. 2. Resist thickness vs x-ray flux for a $0.65 \mu \mathrm{m}$ thick PPI sample.

$\sim 0.3 \mu \mathrm{m}(46 \%)$ regardless of dose. For the $17.5 \mu \mathrm{m}$ thick samples, there is approximately a $2.5 \mu \mathrm{m}$ thickness loss $(15 \%)$ in the exposed regions (see Fig. 3). We could detect no additional loss of resist with additional time in the developer. We hypothesize that there is a loss of a soluble component in the resist matrix near the surface of the exposed regions that impedes bulk resist loss. We recognize that this surface loss of resist is a disadvantage, but this may be remedied by biasing (i.e., compensating) the resist linewidths for device manufacture.

The X-ray sensitivity of PPI was determined as follows. Given a threshold energy of $400 \mathrm{~mJ} / \mathrm{cm}^{2}$ for the $17 \mu \mathrm{m}$ PPI sample (see Fig. 3) together with the spectral distribution of the source (Aladdin), we calculated the absorbed dose distri-

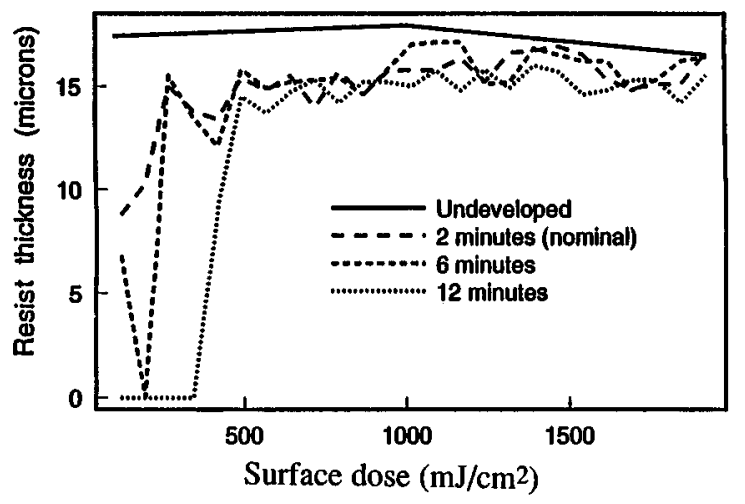

FIG. 3. Resist thickness vs x-ray flux for a $17.0 \mu \mathrm{m}$ thick PPI sample. bution as a function of depth $\left(\mathrm{J} / \mathrm{cm}^{3}\right)$. This was done using the numerical modeling software package TRANSMIT. ${ }^{6}$ The volume dose delivered at the base (which we define as sensitivity) of the $17 \mu \mathrm{m}$ PPI sample is $\sim 60 \mathrm{~J} / \mathrm{cm}^{3}$, which is about two orders of magnitude less than a corresponding PMMA dose would require. Therefore, we can expose a 100 $\mu \mathrm{m}$ thick PPI sample using the same flux necessary for a 1 $\mu \mathrm{m}$ sample of PMMA.

A sample of the PPI over $1000 \mu \mathrm{m}$ thick was prepared. It was exposed with the $800 \mathrm{MeV}$ beam at Aladdin for over $5 \mathrm{~h}$ such that the base of the resist received $\sim 6 \mathrm{~J} / \mathrm{cm}^{3}$ absorbed dose. This small amount of energy at the base of the resist was adequate to expose the negative resist.

The resolution of PPI using X-ray source exposure was also investigated. A mask with $0.5 \mu \mathrm{m}$ features was used to expose a PPI sample $0.65 \mu \mathrm{m}$ thick. The pattern was transferred readily yielding $0.5 \mu \mathrm{m}$ lines, but because of the resist loss the final thickness contracted to $0.35 \mu \mathrm{m}$.

We have demonstrated that photosensitive polyimide is a very promising $\mathrm{x}$-ray resist for micromachining. PPI is roughly one hundred times as sensitive as PMMA, and capable of creating resist structures over $1000 \mu \mathrm{m}$ thick. High quality resist images, with aspect ratios over 10, have been generated routinely. The profiles of these exposures are very vertical and have a wide process latitude in both exposure and development. For thin samples, linewidth contraction was not observed. The major difficulty found was a linewidth contraction for thick samples with a near-constant value of $\sim 2.5 \mu \mathrm{m}$. This may be compensated for by using mask biasing, but it still leaves an artifact at the base of the resist profile. For many micromachining applications, this resist can replace PMMA.

This work was supported in part by NSF Grant ECS9215070. In addition, the authors wish to gratefully acknowledge the support of CXrL at the Synchrotron Radiation Center at the UW-Madison.

${ }^{1}$ E. W. Becker, W. Ehrfeld, P. Hagmann, A. Maner, and D. Munchmeyer, Microelectron. Eng. 4, 35 (1986).

${ }^{2}$ H. Guckel, K. J. Skrobis, T. R. Christenson, and J. Klein, Proc. SPIE 2194, 2 (1993).

${ }^{3}$ J. Mohr, W. Ehrfeld, and D. Muenchmeyer, J. Vac. Sci. Technol. B 6, 2264 (1988).

${ }^{4}$ C. H. Ahn, Y. J. Kim, and M. G. Allen, J. Microelectromech. Syst. 2, 165 (1993).

${ }^{5}$ M. T. Pottiger, D. L. Goff, and W. J. Lautenberger, Proceedings of the 38th Electronic Components Conference, presented at the IEEE Conference, Los Angeles, CA (IEEE, New York, 1988), p. 315.

${ }^{6}$ F. Cerrina, F. Baszler, S. Turner, and M. Khan, Microelectron. Eng. 21, 103 (1993). 